\title{
Age Hardening in a Cu-bearing High Strength Low Alloy Steel
}

\author{
S. S. Ghasemi BANADKOUKI, D. YU and D. P. DUNNE \\ Department of Materials Engineering, The University of Wollongong, Wollongong, NSW 2522, Australia. \\ E-mail: skg66@uow.edu.au
}

(Received on April 25. 1995; accepted in final form on June 19, 1995)

\begin{abstract}
The copper age hardening response in a low alloy variant of the ASTM A710 type steel has been investigated at temperatures of 450,500 , and $550^{\circ} \mathrm{C}$ for three pre-treated conditions (as rolled ferrite, bainitic ferrite, and martensite). Transmission electron microscopy has been used to follow microstructural changes and their relation to the variations in the hardness curves. The results indicate that the age hardening responses of both the martensitic and bainitic ferrite structures are much higher than that of the as rolled condition, and this observation is rationalised in terms of higher solute $\mathrm{Cu}$ content, higher density of dislocations and greater uniformity of solute copper atoms in the pre-treated condition providing a multitude of nucleating sites for copper precipitation. Moreover, it has been found that the peak hardness in the martensitic and bainitic structures was attained when fine $\varepsilon$-copper precipitates are predominantly observed on dislocations. Compared to the martensitic and bainitic structures, the presence of pre-existing interphase $\varepsilon$-copper precipitates, as well as the formation of additional copper-rich clusters and precipitates from supersaturated ferrite contribute to the aging response in the hot rolled condition.
\end{abstract}

KEY WORDS: Cu-bearing low alloy steel; precipitation hardening; $\varepsilon$-Cu precipitates; interphase precipitation; multivariant precipitation; ferrite; bainitic ferrite; martensite.

\section{Introduction}

Research on copper precipitation in iron has been essential in developing new grades Cu-bearing HSLA steels. ${ }^{1-3)}$ Spherical copper-rich bcc clusters can be expected to form during aging because of the similarity in the size of the iron and copper atoms. ${ }^{4}$ However, it has been reported by several investigators ${ }^{5,6)}$ that these bec clusters cannot be observed directly by transmission electron microscopy. Hornbogen et al. ${ }^{6)}$ explained that the only experimental evidence for copper clustering was the time dependence of the appearance of particles of measurable size. Miglin et al..$^{5)}$ argued that the copper clusters were not visible in electron microscopy because of lack of strain fields of sufficient intensity due to the coherency of the clusters with the matrix. However, they reported that evidence for clustering can be inferred from the diffraction patterns. As the copper clusters grow, they become richer in copper content and the lattice parameter decreases, ${ }^{7,8}$ ) which causes an increase in spot separation in electron diffraction patterns. This was observed in their experiments as a splitting of each matrix spot into one larger spot and one smaller spot displaced slightly towards the center of the pattern. These clusters can be transformed to the fcc $\varepsilon$-copper precipitates near the age hardening peak when they are approximately 1 to $2.4 \mathrm{~nm}$ in size. ${ }^{6,7)}$

Goodman et $a l^{7}{ }^{7}$ investigated details of copper precipitation in iron by using field ion microscopy. They found that coherent, copper-rich clusters formed in ferrite during aging at $500^{\circ} \mathrm{C}$ and coarsened by bulk diffusion. These clusters contained less copper than the equilibrium epsilon phase, which is relatively pure copper and forms from the clusters during overaging. The alloy $(\mathrm{Fe}-1.4 \% \mathrm{Cu})$ reached its peak strength while the precipitates were still bcc clusters with an average diameter of $2.4 \mathrm{~nm}$ and an average copper content of only $50 \%$, but the precipitate density remained constant until the peak strength was reached, then decreased during overaging due to selective dissolution and coarsening.

In general, the age hardening behaviour of copper in steel depends on the original copper content, degree of supersaturation, and aging time and temperature. These factors are related to each other during aging treatment and only the overall effect can be observed from the aging curve. Therefore, these factors should be carefully examined in order to investigate the separate effect of each parameter on the copper age hardening response. In this study, the age hardening of various pre-treated microstructures (ferrite, bainitic ferrite, and martensite) due to copper-based precipitation has been investigated in an ASTM A710 type HSLA plate steel.

\section{Materials and Experimental Procedure}

The steel used in the present study was CR HSLA80 steel developed by BHP Steel, SPPD, Port Kembla, Australia. This steel was produced by a thermo-mechanical controlled processing (TMCP) route, with the as received material consisting of a banded ferrite and pearlite structure as shown in Fig. 1. The thickness of the plate was $10 \mathrm{~mm}$ and the chemical composition is given in Table 1. 
To study the precipitation hardening of copper, a series of samples were heat treated under different conditions and then cooled to room temperature at various cooling rates: (i) water quenching after austenitisation at $900^{\circ} \mathrm{C}$ for $30 \mathrm{~min}$ (martensite); (ii) austenitising at $1200^{\circ} \mathrm{C}$ for $15 \mathrm{~min}$ and then holding in a salt bath at $440^{\circ} \mathrm{C}$ for $5 \mathrm{sec}$ before water quenching (bainitic ferrite); and (iii) the as rolled condition (ferrite). After the heat treatment, the samples were submitted to an aging treatment at different aging temperatures for various period of times, as shown schematically in Fig. 2. Hardness measurements were made with a $10 \mathrm{~kg}$ load and are reported as Vickers hardness numbers (VHN). Thin foil specimens were prepared by a twin polishing technique using a solution consisting of $95 \%$ acetic acid and $5 \%$ perchloric acid. In some cases, the perforated thin foils were ion beam thinned for approximately $3 \mathrm{~h}$

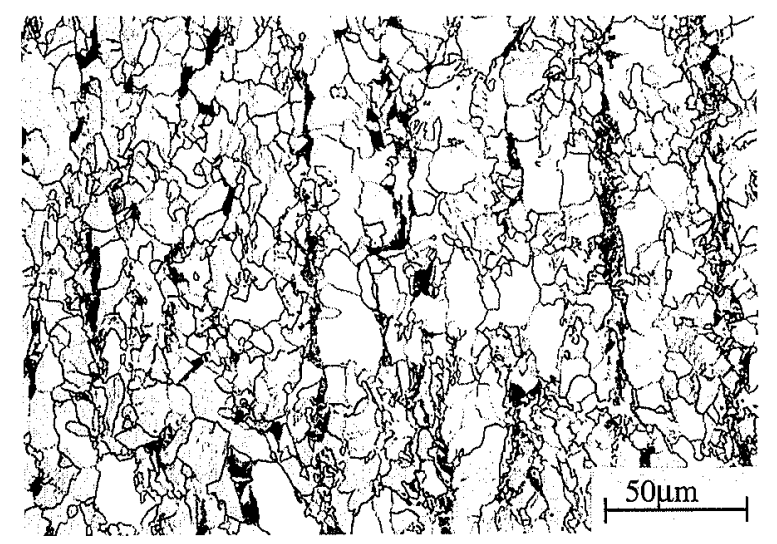

Fig. 1. Optical micrograph of as received hot rolled plate steel ( $2.5 \%$ nital). Longitudinal section containing the rolling direction.

Table 1. Chemical composition (in $w t \%$ ) of the CR HSLA80 steel investigated.

\begin{tabular}{ccccc}
\hline $\mathrm{C}$ & $\mathrm{Mn}$ & $\mathrm{Si}$ & $\mathrm{Ni}$ & $\mathrm{Cu}$ \\
\hline 0.05 & 1.40 & 0.25 & 0.85 & 1.10 \\
\hline $\mathrm{Nb}$ & $\mathrm{Ti}$ & $\mathrm{P}$ & $\mathrm{S}$ & $\mathrm{Cr}$ \\
\hline 0.02 & 0.013 & 0.012 & 0.003 & - \\
\hline
\end{tabular}

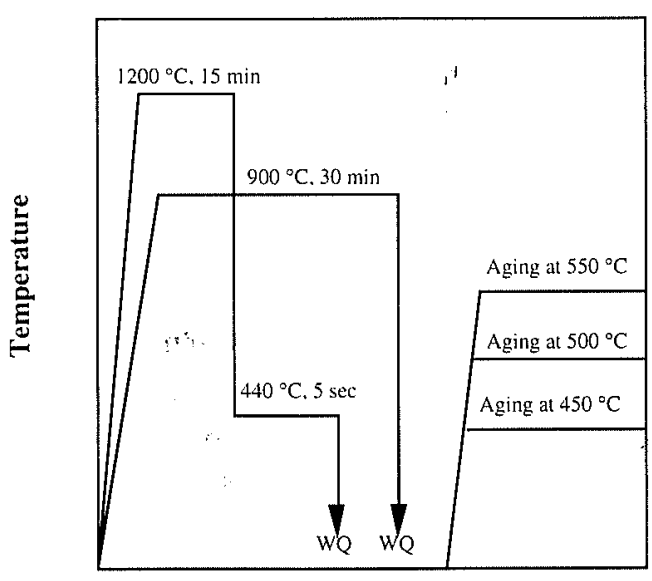

Time

Fig. 2. Schematic diagrams showing pre-treating and hardening procedures. at a $9^{\circ}$ specimen angle in an Edwards IBT 200 ion beam thinning unit. Observations were carried out in' a JEOL $2000 \mathrm{FX}$ electron microscope operated at $200 \mathrm{kV}$.

\section{Results}

\subsection{Isothermal Aging Curves}

Figures $\mathbf{3}$ and $\mathbf{4}$ are plots of hardness versus aging time for both as rolled and bainitic ferrite material aged at 450,500 , and $550^{\circ} \mathrm{C}$. As the aging time increased, the hardness increased gradually in both cases until the peak hardness values were attained. It can be seen that the age hardening response of the bainitic ferrite microstructure was much higher than that of the as rolled material. This result stems from the higher solute $\mathrm{Cu}$ content and the greater density of dislocations in the pre-treated material because of the displacive mechanism of bainitic ferrite formation. A higher peak hardness and a longer time to reach peak hardness can be clearly observed for the lower aging temperature for both of the pre-treated microstructures (Figs. 3, 4).

Hardness curves for as quenched material aged iso-

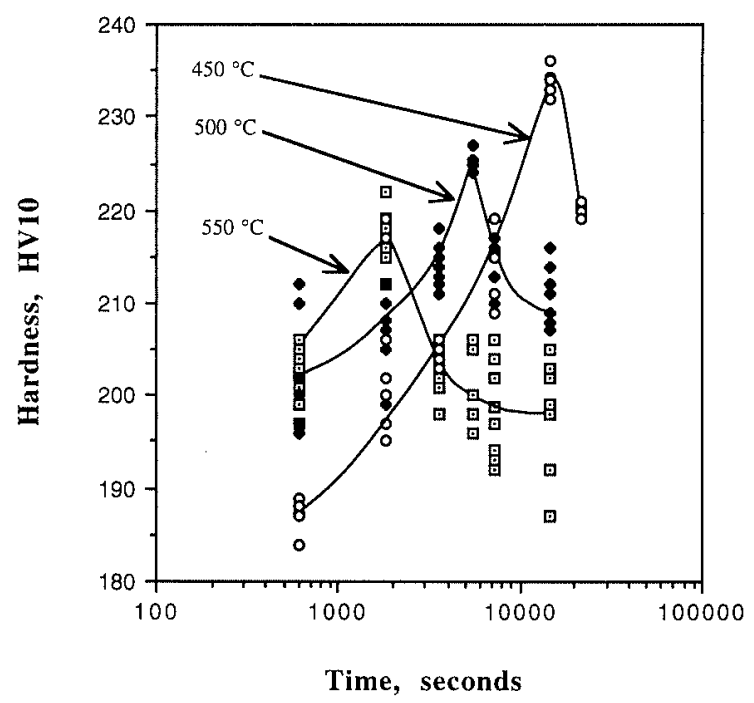

Fig. 3. Effect of aging time on the hardness in the as rolled material.

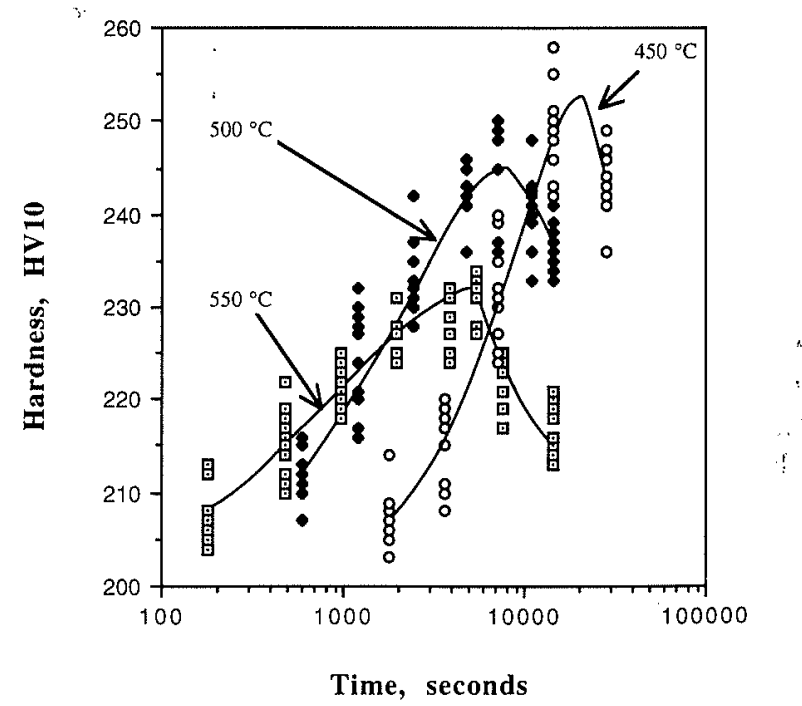

Fig. 4. Isothermal aging curves for the samples with bainitic ferrite structure, formed at $440^{\circ} \mathrm{C}$ after $5 \mathrm{sec}$. 
thermally at 450,500 , and $550^{\circ} \mathrm{C}$ are shown in Fig. 5 . In this case, it is obvious that both copper age hardening and tempering phenomena occurred competitively during the aging process. Although the real age hardening effect is partially neutralised by tempering in as quenched samples, the hardness curves show that copper age hardening provides a significant secondary hardening effect. Compared to the other two starting conditions, the aging reaction was slightly accelerated by quenching.

Figure 6 represents the copper age hardening response at $500^{\circ} \mathrm{C}$ for the various pre-treated materials (as rolled, bainitic ferrite, and martensitic structures). Quenched material showed a higher general level of hardness than either bainitic ferrite or as rolled polygonal and quasipolygonal ferrite. The high hardness is in part due to the high density of dislocations generated during quenching, but the development of a significant peak in hardness still indicates the presence of an appreciable copper age hardening effect.

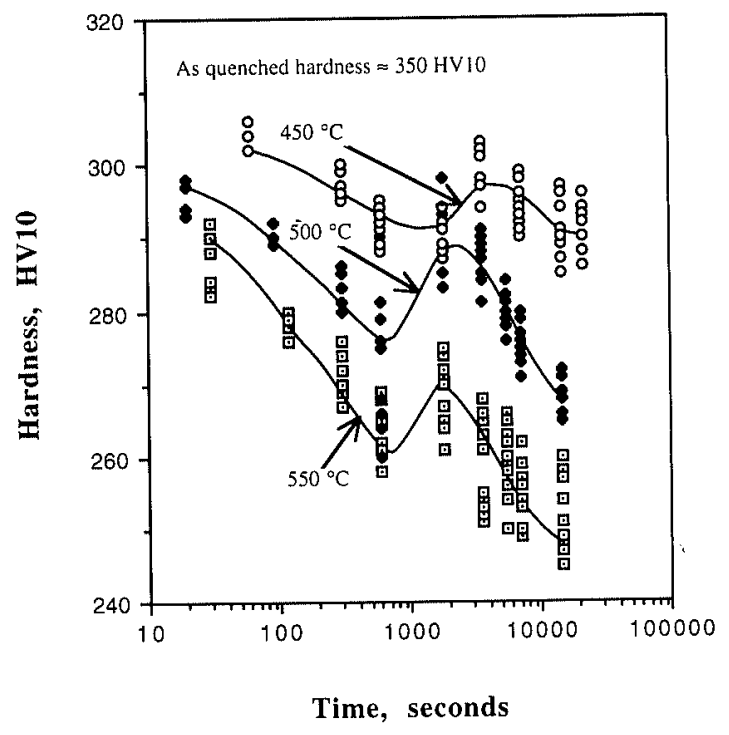

Fig. 5. Effect of aging time on the hardness of as quenched steel.

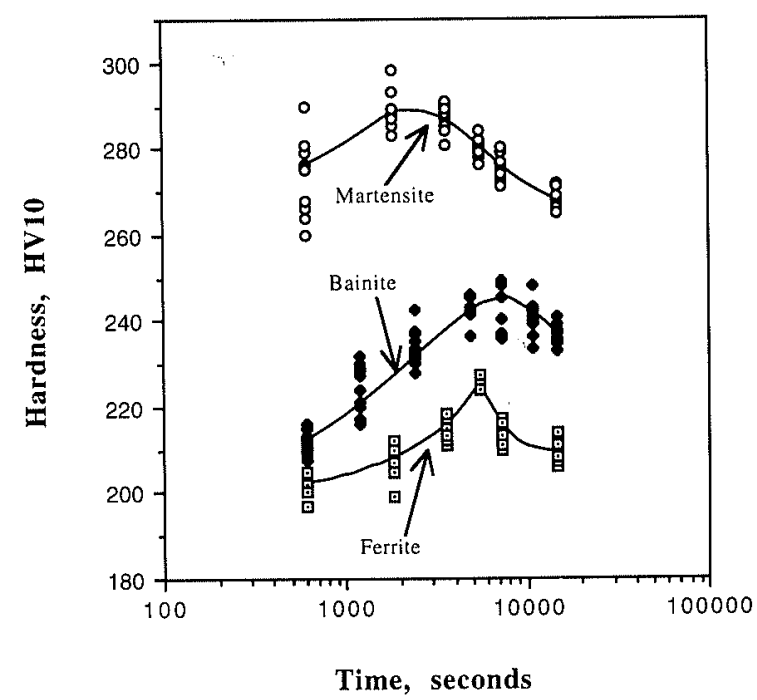

Fig. 6. Effect of aging time at $500^{\circ} \mathrm{C}$ on the hardness of various pre-treated microstructures.

\subsection{Copper Precipitation}

\subsubsection{Bainitic Ferrite Structure}

Figures 7(a), 7(b), and 7(c) are micrographs of bainitic ferrite aged at $550^{\circ} \mathrm{C}$ for 3,90 , and $128 \mathrm{~min}$, respectively. As can be observed, the bainitic ferrite laths contain a high density of dislocations. By correlating the aged structures (Figs. 7(a), (b), and (c)) with the hardness measurements (Fig. 4), it can be seen that peak hardness (after $90 \mathrm{~min}$ ) occurred when very fine $\varepsilon$-copper precipitates were present on the dislocations, (Fig. 7(b)). With further growth of the precipitates by selective coarsening, the hardness begins to drop and the overaged precipitates are easily distinguished by electron microscopy (Fig. 7(c)).

\subsubsection{As Rolled Condition}

Copper precipitation was observed in some areas of the as rolled samples. Figures 8(a) and $\mathbf{8 ( b )}$ are bright field (BF) and dark field (DF) micrographs which reveal interphase $\varepsilon$-Cu precipitates in an apparently random distribution, but displaying the same variant of the Kurdjumov-Sachs orientation relationship. ${ }^{9)}$ For other foil orientations, sheets of $\varepsilon$-Cu precipitates with regular spacings were observed. This precipitate morphology is identical with the interphase precipitation observed and
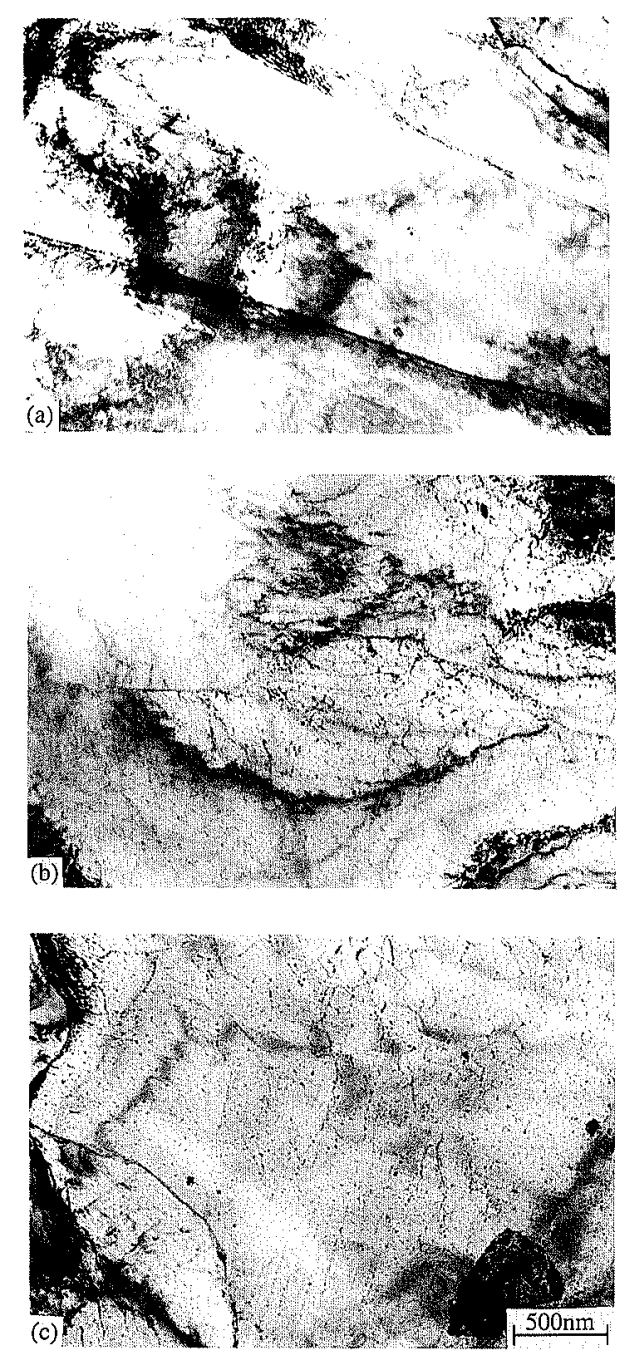

Fig. 7. Bright field TEM micrographs of the bainitic ferrite structure aged at $550^{\circ} \mathrm{C}$ for: (a) $3 \mathrm{~min}$; (b) $90 \mathrm{~min}$; (c) $128 \mathrm{~min}$. 
described by Howell et al. ${ }^{10)}$ and Ricks et al. ${ }^{11)}$ during isothermal transformation of $\mathrm{Fe}-\mathrm{Cu}-\mathrm{Ni}$ alloys.

Figures 9(a) and 9(b) are TEM bright field micrographs taken from the as rolled samples aged at $500^{\circ} \mathrm{C}$ for 90 and $240 \mathrm{~min}$, respectively. The as rolled sample aged for $90 \mathrm{~min}$ displayed peak hardness and the structure consisted of layers of fine $\varepsilon$-copper, as well as
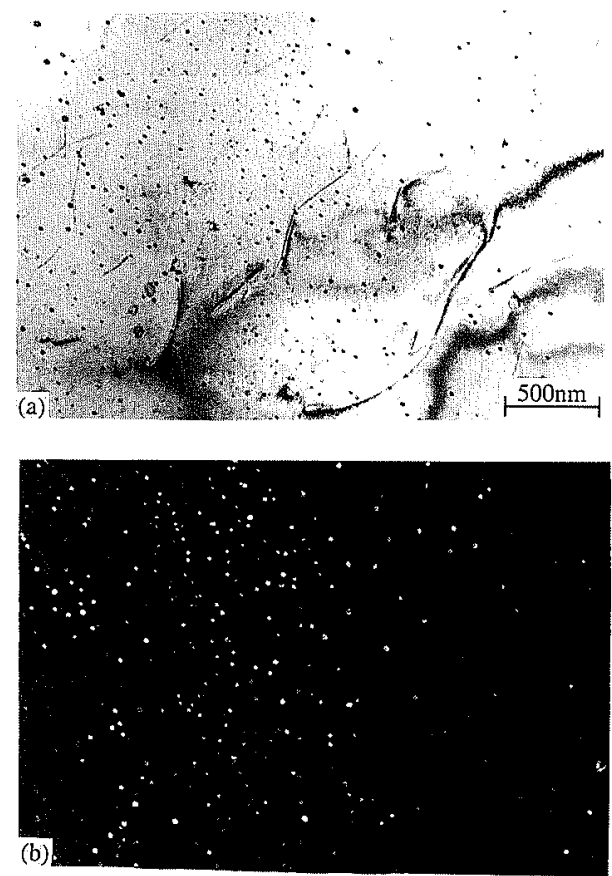

Fig. 8. Apparently random distribution of interphase $\varepsilon-\mathrm{Cu}$ precipitates in the hot rolled plate steel: (a) bright field (BF) micrograph showing both coarse and fine copper precipitates; (b) centred dark field (CDF) image taken from a $\{111\} \varepsilon-\mathrm{Cu}$ reflection revealing particles in the same variant of the $\mathrm{K}-\mathrm{S}$ orientation relationship.
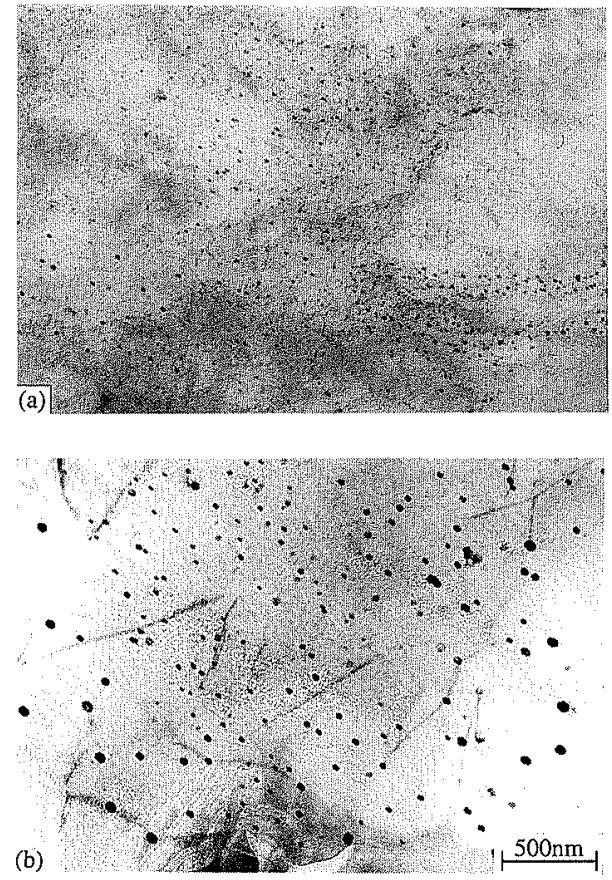

Fig. 9. Bright field (BF) TEM micrographs taken from as rolled samples aged at $500^{\circ} \mathrm{C}$ for: (a) $90 \mathrm{~min}$; (b) $240 \mathrm{~min}$. relatively coarse $\varepsilon$-copper particles. The coarse precipitates are well over-aged and are unlikely to contribute strongly to the peak hardness. They probably formed in ferrite by interphase precipitation on cooling after hot rolling. ${ }^{12,13)}$ After aging at $500^{\circ} \mathrm{C}$, additional copperrich clusters and precipitates form from supersaturated ferrite, and coarsening of pre-existing $\varepsilon$-copper particles also occurs. The precipitates were generally coarser than those formed in the bainitic ferrite aged at the higher temperature of $550^{\circ} \mathrm{C}$ (Figs. 7(a), (b), and (c)).

Figures 10(a) and 10(b) are bright field and dark field micrographs taken from the hot rolled sample aged at $500^{\circ} \mathrm{C}$ for $90 \mathrm{~min}$. The interphase precipitation mode is inferred because of the layer precipitation morphology. The electron diffraction pattern showing matrix and $\varepsilon-\mathrm{Cu}$ reflections, and its schematic representation are displayed in Figs. 10(c) and 10(d). The orientation relationship between the copper precipitates and ferrite matrix was verified to correspond to one of the variants of the Kurdjumov-Sachs $(\mathrm{K}-\mathrm{S})^{9)}$ orientation relationship developed between the fcc (copper rich) and bcc (ferrite) structures. This result indicates that copper precipitation occurred in ferrite.

In contrast to dominance of interphase $\varepsilon-\mathrm{Cu}$ precipitation in the as rolled condition, the $\mathrm{Cu}$-rich precipitates were usually nucleated intragranularly on dislocations in the bainitic ferrite structure. Figure 7 (c) shows a typical bright field TEM micrograph taken from a bainitic ferrite sample in the over-aged condition $\left(128 \mathrm{~min}\right.$ at $\left.550^{\circ} \mathrm{C}\right)$. As can be seen, the $\varepsilon$-copper precipitates are predominantly sited on dislocations in a virtually random distribution.

Comparison of Figs. 10 and $7(\mathrm{c})$ indicates that the bainitic ferrite, which forms at lower transformation temperatures response to more rapid cooling, is more
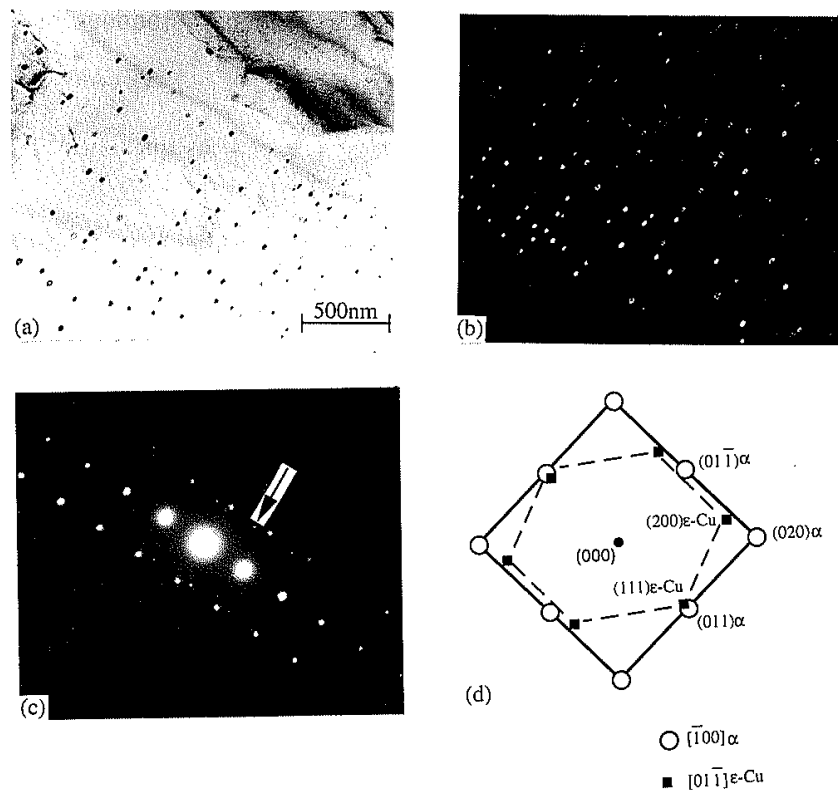

Fig. 10. Precipitation of $\varepsilon-\mathrm{Cu}$ in the hot rolled sample aged at $500^{\circ} \mathrm{C}$ for $90 \mathrm{~min}$ : (a) $\mathrm{BF}$ image; (b) $\mathrm{CDF}$ image from the $(200)_{c-c u}$ reflection indicated in (c); (c) diffraction pattern showing ferrite and $\varepsilon-\mathrm{Cu}$ reflections; (d) schematic representation of diffraction pattern. 
heavily dislocated than polygonal ferrite and contains finer $\mathrm{Cu}$ precipitates in the aged condition. Evidence for long range diffusion of substitutional solute atoms in polygonal ferrite is indicated by the presence of coarse $\varepsilon$-copper precipitates in the hot rolled condition (Fig. 8). During aging, the pre-existing $\mathrm{Cu}$ particles act as sites for further relies of remnant $\mathrm{Cu}$ supersaturation, leading to particle coarsening. Additional in situ clustering and precipitation of fine $\mathrm{Cu}$ rich particles also occurs, increasing the hardness. When the transformation temperature is significantly lower, diffusion and precipitation of $\mathrm{Cu}$ are retarded leading to $\mathrm{Cu}$ supersaturation and relatively precipitate free-bainitic ferrite.

\subsubsection{Martensitic Structure}

Precipitation of $\varepsilon-\mathrm{Cu}$ was not detected in the as quenched martensitic structure, as would be expected for the fast cooling rate generated by water quenching (Fig. 11(a)). However, Cu-rich precipitates can be formed from supersaturated solid solution during subsequent aging treatment because of the decrease in the solubility of copper in ferrite with decreasing temperature. ${ }^{6)}$ Figure 11(b) shows a bright field (BF) micrograph taken from a martensitic sample aged at $550^{\circ} \mathrm{C}$ for $30 \mathrm{~min}$. After this treatment, the alloy exhibited the peak age hardening response, associated with fine $\varepsilon$-Cu precipitates randomly distributed on dislocations. In samples aged for longer times, $\langle 111\rangle$ zone electron diffraction patterns of the martensitic matrix showed multivariant reflections from $\varepsilon$-Cu particles. A typical $\varepsilon$ - $\mathrm{Cu}$ precipitate dispersion associated with multiple variants of the $\mathrm{K}-\mathrm{S}$ orientation relationship is shown in Fig. 12. The reflections from the diffraction pattern of the martensitic structure in Figs. 12(c) and 12(e) display a $\langle 111\rangle$ zone axis with two orientation variants of the $\varepsilon$-Cu precipitate particles. The
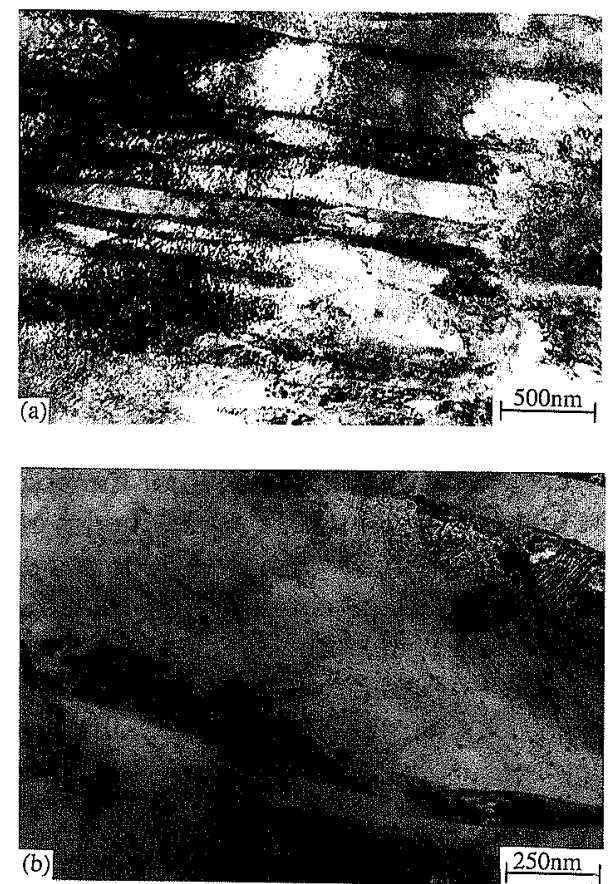

Fig. 11. TEM micrographs of martensitic samples: (a) as quenched (precipitate free); (b) quenched and aged $30 \mathrm{~min}$ at $550^{\circ} \mathrm{C}$ showing fine $8-\mathrm{Cu}$ precipitates in association with dislocations.
DF images corresponding to the two variants are shown in Figs. 12(b) and 12(d).

\section{Discussion}

\subsection{Age Hardening Sequence for Various Pre-treated Microstructures}

A significant hardening peak was observed on aging at temperatures of 450,500 , and $550^{\circ} \mathrm{C}$, not only in the martensitic structure but also in the bainitic ferrite and the as rolled ferrite (Figs. 3-5). It is evident that the extent of age hardening increases with decreasing aging temperature, and this effect can be attributed to the progressively finer precipitate dispersions generated at lower aging temperatures (Fig. 13). On further holding at the aging temperature, the hardness decreased because of selective coarsening and dissolution of precipitates (Figs. 9, 12). As would be expected, the rate of softening increased with increasing aging temperature (Figs. 3-5).

The overall effect of quenching on the age hardening behaviour of this alloy is due to the contribution from two processes: age hardening as well as tempering of the martensite. The formation of $\mathrm{Cu}$-rich precipitates during aging leads to hardening; but tempering by carbide formation and coarsening, and modification of the
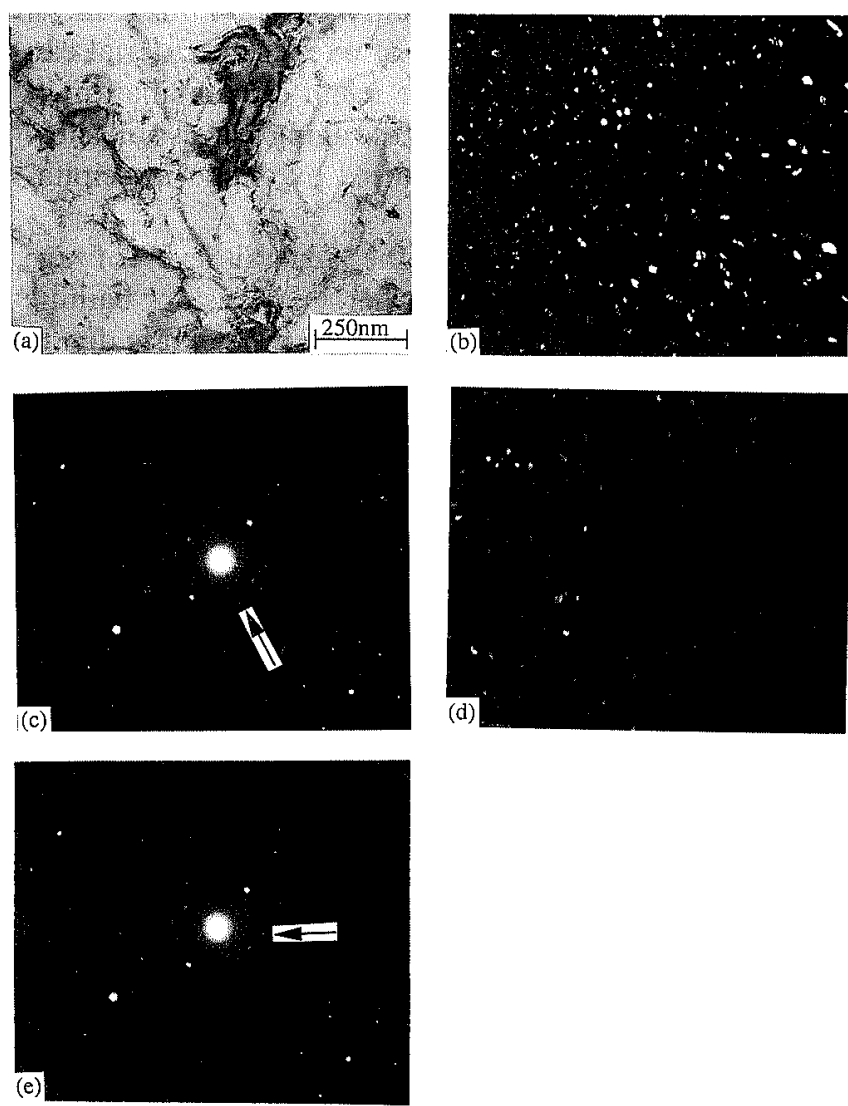

Fig. 12. Preferential coarsening of multi-variant $\varepsilon$-Cu precipitates from the martensitic specimen aged at $550^{\circ} \mathrm{C}$ for 240 min: $\mathrm{BF}$ image; (b) $\mathrm{CDF}$ image from the faint $\{11\}_{s-c u}$ reflection indicated in (c); (c) corresponding diffraction pattern (near $\langle 111\rangle_{\mathrm{M}}$ zone axis); (d) $\mathrm{CDF}$ image from another faint $\{111\}_{\varepsilon-\mathrm{Cu}}$ reflection indicated in (e); (e) corresponding diffraction pattern (near $\langle I I I\rangle_{M}$ zone axis). These reflections are consistent with multiple variants of the K-S orientation relationship. 

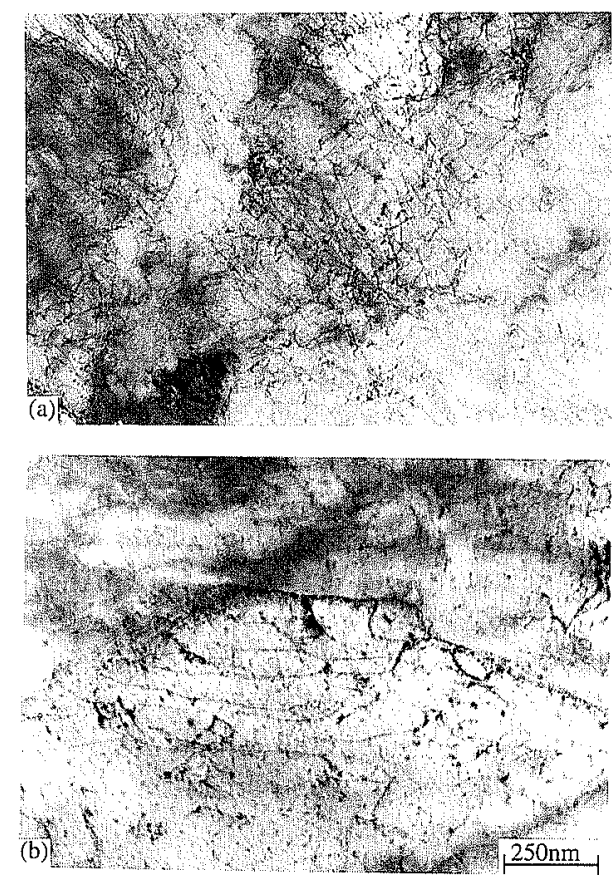

Fig. 13. Fine $\varepsilon-\mathrm{Cu}$ precipitates associated with the peak age hardening of bainitic ferrite structure aged: (a) 128 min at $500^{\circ} \mathrm{C}$; (b) $90 \mathrm{~min}$ at $550^{\circ} \mathrm{C}$.

dislocation structure will result in a decrease in hardness. The form of the aging curves of quenched material can therefore be considered to be a result of combination of these two processes. However, the aging curves still show a significant hardness peak caused by copper precipitation hardening (Fig. 5).

The results showed that the general level of age hardening decreased in the order: martensitic; bainitic ferrite and as rolled ferrite (Fig. 6). This trend is due in part to the displacive mechanism of bainitic ferrite and martensitic formation and partly to the formation of a supersaturated solid solution with respect to $\mathrm{Cu}$. The excess solute copper will come out of solution at rates which depend on the aging temperature and time. In addition to the supersaturated solid solution, the higher dislocation density generated by low temperature transformation to ferrite provides a multitude of nucleation sites for copper-rich precipitates, resulting in finer and more homogeneously distributed precipitates (Figs. 7, $11(\mathrm{~b})$, and 12). The presence of multivariant precipitation on aging indicates that the bainitic ferrite and martensitic structures have formed fast enough at sufficiently low temperatures to be supersaturated with respect to $\varepsilon-\mathrm{Cu}$ precipitation.

In contrast to the bainitic ferrite and martensitic structures, interphase $\varepsilon-\mathrm{Cu}$ precipitates formed from ferrite during austenite decomposition on cooling after hot rolling (Fig. 8). On coarsening, these precipitates become incoherent with respect to the ferrite matrix and as such, do not contribute significantly to age hardening. Clearly, the full hardening potential of the alloy was not achieved in the TMCP condition and a more effective treatment to increase the hot rolled strength would involve accelerated cooling to obtain more highly supersaturated ferrite after hot rolling and prior to aging.
According to previous work on the effect of microstructures on the mechanical properties of a $\mathrm{Cu}$-bearing HSLA steel, ${ }^{14)}$ the optimum combination of fracture toughness and transition temperature resulted from microstructures containing a mixture of coherent (bcc clusters) and incoherent $(\varepsilon-\mathrm{Cu})$ copper precipitates. In the peak-aged microstructures of the present study (particularly for the martensitic and bainitic ferrite cases), a very fine $\varepsilon$-copper precipitate distribution was usually observed on dislocations, which evidently acted as sites for precipitate nucleation and growth (Figs. 7(b), 11(b)). These fine $\varepsilon$ - $\mathrm{Cu}$ precipitates contribute to strengthening by precipitation hardening and unresolved bcc clusters and fcc $\varepsilon$ - $\mathrm{Cu}$ particles provide an additional increment in strength. Coarser incoherent $\varepsilon$-copper precipitates have been found to inhibit localised slip and formation of dislocation pile ups at grain boundaries. ${ }^{5)}$ The current observations suggest that the formation of a very fine $\varepsilon$-Cu precipitate distribution is the principal hardening mechanism in this alloy system and that over-aging is due to the coarsening of incoherent $\varepsilon-\mathrm{Cu}$ precipitates.

\subsection{Effect of Aging Temperature on Aging Behaviour of Various Pre-treated Microstructures}

The age hardening results indicated that the aging sequence was significantly accelerated by aging temperature for these pre-treated structures used in this study (Figs. 3-5). The material with the bainitic ferrite structure reached peak hardness after $240 \mathrm{~min}$ at $450^{\circ} \mathrm{C}$, but it took $128 \mathrm{~min}$ at $500^{\circ} \mathrm{C}$ and $90 \mathrm{~min}$ at $550^{\circ} \mathrm{C}$. It is obvious that increase in temperature accelerates aging of the alloy due to increase in diffusion rate which in turn enhances both nucleation and growth of $\mathrm{Cu}$-rich precipitates. On the other hand, for a lower aging temperature, both nucleation and growth rates of copper rich precipitates are low because of low diffusivity of solute elements. In addition, the dislocation mobility is sluggish at lower temperature, which in turn leads to a finer copper precipitation on dislocation during aging (Fig. 13).

It should be noted that the growth rate of copper-rich precipitates increases as the temperature increases and this can be seen from the bainitic ferrite structures in the samples with peak hardness aged at 500 and $550^{\circ} \mathrm{C}$ (Fig. 13). The $\varepsilon$-Cu precipitates in the sample aged at $500^{\circ} \mathrm{C}$ are much finer compared to those of the sample aged at $550^{\circ} \mathrm{C}$, indicating that growth of the precipitates is faster at higher temperature. Faster kinetics of copper precipitation reduces the aging time required to reach the peak hardness significantly, but at the cost of hardening capacity (Table 2). The data in Table 2 show that the values of $\Delta \mathrm{H}$ (difference between the pre-treated hardness and peak hardness) for the various pre-treated microstructures decrease with increasing aging temperature.

\section{Conclusions}

(1) Although precipitation strengthening in low carbon $\mathrm{Cu}$-bearing steels is considered to be due to formation of coherent copper rich clusters, the peak 
Table 2. Age hardening of various pre-treated structures at different aging temperatures.

\begin{tabular}{clccc}
\hline Temperature, ${ }^{\circ} \mathrm{C}$ & Structures & Hs & Hp & $\Delta \mathrm{H}$ \\
\hline \multirow{2}{*}{450} & Bainitic ferrite & 200 & 253 & 53 \\
& Polygonal ferrite & 185 & 234 & 49 \\
500 & Bainitic ferrite & 200 & 245 & 45 \\
& Polygonal ferrite & 185 & 232 & 38 \\
550 & Banitic ferrite & 200 & 233 & 33 \\
& Polygonal ferrite & 185 & 216 & 31 \\
\hline
\end{tabular}

Hs, Hardness of solution treated sample;

$\mathrm{Hp}$, Peak hardness of aged sample;

$\Delta \mathrm{H}$, Difference between $\mathrm{Hp}$ and $\mathrm{Hs}$.

hardness in the CR HSLA80 was associated with very fine $\varepsilon-\mathrm{Cu}$ precipitates formed on dislocations. The hardness decreased with overaging as a result of selective coarsening and dissolution of copper precipitates.

(2) Age hardening by $\mathrm{Cu}$-rich precipitates depended strongly on the pre-treated condition, decreasing in peak hardness level in the order: as quenched (martensitic); isothermally transformed (bainitic ferrite) and as rolled condition (polygonal ferrite).

(3) The existence of a high dislocation density accelerated and refined the formation of coherent copper rich clusters and fine coherent $\varepsilon-\mathrm{Cu}$ precipitates, and subsequently aging was accelerated and intensified. The high dislocation density provided a multitude of nucleating sites for copper precipitation, leading to finer and more homogeneously distributed coherent particles.

(4) Increasing the aging temperature significantly accelerated formation and coarsening of the copper rich precipitates.

(5) Significant copper precipitation occurred in the thermo-mechanical controlled processing condition and therefore the full strengthening potential of the alloy was not achieved by the subsequent aging treatment. The maximum strengthening by precipitation hardening would be expected for processing which involves accelerated cooling after finish rolling to form more highly supersaturated ferrite prior to aging. Water quenching to form martensite and quenching to $440^{\circ} \mathrm{C}$ to form bainitic ferrite suppressed precipitation during cooling, resulting in increased supersaturation of $\mathrm{Cu}$ in the matrix.

\section{Acknowledgments}

One of the authors (S. S. Ghasemi Banadkouki) is grateful to the Ministry of Culture and Higher Education of Iran for providing a scholarship, and to Dr. D. Wexler for helpful TEM discussions at the University of Wollongong. The support of BHP Steel, SPPD, Port Kembla, in provision of material and technical information is gratefully acknowledged.

\section{REFERENCES}

1) A. Youle and B. Ralph: Met. Sci. J., 6 (1972), 149.

2) M. R. Krishnadev, S. Dionne, J. T. Bowker and J. T. McGrath: Microalloying and Thermo-mechanical Processing of Copper and Boron Containing High Strength Steels, Int. Conf. on Physical Metallurgy of Thermo-mechanical Processing of Steels and Other Metals, Tokyo, (1988), 511.

3) M. R. Krishnadev and A. Galibos: Met. Technol., June, (1974), 300.

4) A. Guinier: Z. Metallkd., 43 (1952), 217.

5) M. T. Miglin, J. P. Hirth, A. R. Rosenfield and W. A. T. Clark: Metall. Trans. A, 17A (1986), 791.

6) E. Hornbogen and R. C. Glenn: Trans. Metall. Soc. AIME, 218 (1960), 1064.

7) S. R. Goodman, S. S. Brenner and J. R. Low, Jr.: Metall. Trans., 4 (1973), 2363.

8) D. C. Hilty and W. Crafts: Trans. AIME, 188 (1950), 414.

9) G. Kurdjumov and G. Sachs: Z. Phys., 64 (1930), 325.

10) P. R. Howell, R. A. Ricks and R. W. K. Honeycombe: J. Mater. Sci., 15 (1980), 376.

11) R. A. Ricks, P. R. Howell and R. W. K. Honeycombe: Metall. Trans. A, 10A (1979), 1049.

12) R. W. K. Honeycombe: Metall. Trans. A, 7A (1976), 915

13) R. A. Ricks, P. R. Howell and R. W. K. Honeycombe: J. Mater. Sci., 14 (1980), 562.

14) M. T. Miglin, J. P. Hirth and A. R. Rosenfield: Metall. Trans. $A$, 14A (1983), 2055 